\title{
ПРАВО НА СВОБОДУ И ЛИЧНУЮ НЕПРИКОСНОВЕННОСТЬ В РОССИЙСКОМ УГОЛОВНОМ СУДОПРОИЗВОДСТВЕ: ТЕРМИНОЛОГИЧЕСКИЕ ПРОБЛЕМЫ
}

\begin{abstract}
АНнотАЦИЯ. В статье рассматриваются предложения по совершенствованию уголовно-процессуального законодательства. Обосновывается необходимость внесения изменений в ст. 10 Уголовно-процессуального кодекса РФ «Неприкосновенность личности». Указывается на несоответствие названия этой статьи основным международно-правовым актам, действующей Конституции РФ и общему содержанию Уголовно-процессуального кодекса РФ. На основании проведенного анализа предлагается новое название рассматриваемой статьи. При этом делается акцент на существенные изменения, положившие начало модернизации законодательства в этой сфере и внесенные в Уголовно-процессуальный кодекс РФ в 2009 г., которые касаются запрета на избрание меры пресечения в виде заключения под стражу по делам, связанным с отдельными преступлениями в сфере экономики. Отмечается необходимость продолжения обновления уголовно-процессуального законодательства, сохранившего черты и терминологию советского права, которые «не вписываются» в современную модель развития России.

кЛюЧЕВЫЕ СЛОВА. Уголовное судопроизводство; уголовно-процессуальное право; право на свободу; неприкосновенность личности; личная неприкосновенность; меры уголовно-процессуального принуждения; меры пресечения; заключение под стражу; арест.

ФИНАНСИРОВАНИЕ. Государственное задание Министерства образования и науки РФ в 2014-2016 гг. № 29.1247.2014/К на выполнение научно-исследовательских работ в сфере научной деятельности в рамках проектной части проекта № 1247 «Пределы ограничения прав личности в уголовном судопроизводстве в целях обеспечения национальной безопасности государства: уголовно-процессуальный и криминалистический анализ».
\end{abstract}

ИНФОРМАЦИЯ О СТАТЬЕ. Дата поступления 22 июня 2016 г.; дата принятия к печати 12 июля 2016 г.; дата онлайн-размещения 30 сентября 2016 г.

P. O. Prelovsky Baikal State University, Irkutsk, Russian Federation

\section{RIGHT FOR LIBERTY AND PERSONAL INVIOLABILITY IN RUSSIAN CRIMINAL PROCEDURE: TERMINOLOGICAL PROBLEMS}

\begin{abstract}
The article considers proposals on improving the criminal procedure Legislation. It substantiates the necessity of introducing changes into Article 10 of the Criminal Procedure Code of RF «personal inviolability». It points at discrepancy of the name of this article to the main international legal acts, to the existing Constitution of RF and the general content of the Criminal Procedure Code of RF. On the basis of an analysis made, it offers a new name of the article under consideration. At his, an emphasis is laid on the significant changes that initiated modernization of the legislation in this sphere and introduced into the Criminal Procedure Code of RF in 2009 that related to the ban on applying a measure of restraint in form of custodial placement in cases connected with crimes in the economic sphere. The article notes the necessity of continuing the renewal of the Criminal Procedure Legislation that have preserved the
\end{abstract}

(C) П.О. Преловский, 2016

\section{Baikal Research Journal}


features and terminology of the Soviet Law, which are not congruent with the modern model of Russia's development.

KEYWORDS. Criminal procedure; criminal procedure law; right for liberty; security of person; personal inviolability; measures of criminal procedure coercion; preventive measures; placement in custody; arrest.

FINANCING. This work has been supported by the Government Research Assignment No 29.1247.2014/K within the framework of the project «Limits for restriction of rights of an individual in criminal court proceedings for ensuring national security: criminal procedural and forensic analysis».

ARTICLE INFO. Received June 22, 2016; accepted July 12, 2016; available online September 26, 2016.

Легко себе представить, какой опасности подвергается личная свобода граждан, когда в законодательстве нет ответа на указанные вопросы...

\section{Н.Н. Полянский}

Право на свободу и личную неприкосновенность является одним из фундаментальных (основных) прав человека [1, с. 143; 2, с. 213-214; 3, с. 266-267]. Оно, наряду с правом на жизнь, честь и достоинство, является естественным неотчуждаемым правом, принадлежащим каждому человеку с рождения $[4$, с. $123 ; 5$, с. 105 ; 6 , с. 62]. Будучи основным, оно гарантирует человеку осуществление нормальной жизнедеятельности [7, с. 18]. Ограничение права на свободу и личную неприкосновенность означает прекращение этой жизнедеятельности и исключение члена общества из сферы его привычного общения, интересов и функционирования в общественной жизни. Полагаем, что существенное ограничение этого права, какое имеет место быть при избрании, прежде всего, таких мер пресечения, как заключение под стражу и домашний арест, должно иметь под собой также и существенные основания. Вместе с тем, вопросы, связанные с этим правом, затрагивают не только институт мер пресечения, но и многие другие институты уголовного судопроизводства, например, уголовного преследования, подозрения (см.: [8, с. 17-20]).

До 2009 г. представителями юридической науки (см. напр.: [9, с. 59; 10, с. 60-65]), а также Конституционным Судом Российской Федерации ${ }^{1}$ указывалось на избыточность избрания такой меры уголовно-процессуального принуждения, как заключение под стражу, а также на недопустимость ее необоснованного применения. Отмечалась также необходимость бо́льшего использования мер пресечения, альтернативных заключению под стражу. В этой связи учеными-процессуалистами приводились случаи необоснованного ограничения права на свободу и личную неприкосновенность: недостаточность оснований для задержания, ареста и его продления, чрезмерность применения этих мер. В немалом количестве дел в итоге назначалось наказание, не связанное с лишением свободы, хотя лицо до провозглашения приговора находилось под стражей. Соответственно, избрание заключения под стражу во многом было избыточно.

${ }^{1}$ По делу о проверке конституционности ряда положений Уголовно-процессуального кодекса Российской Федерации, регламентирующих порядок и сроки применения в качестве меры пресечения заключения под стражу на стадиях уголовного судопроизводства, следующих за окончанием предварительного расследования и направлением уголовного дела в суд, в связи с жалобами ряда граждан : постановление Конституц. Суда РФ от 22 марта 2005 г. № 4-П // Собрание законодательства РФ. 2005. № 14. Ст. 1271; Об отказе в принятии к рассмотрению жалобы гражданина Ховалыга Валерия Сарыг-Ооловича на нарушение его конституционных прав частью третьей статьи 255 Уголовно-процессуального кодекса Российской Федерации : определение Конституц. Суда РФ от 21 дек. 2004 г. № 468-О // Вестник Конституционного Суда РФ. 2005. № 3.

\section{Baikal Research Journal}

электронный научный журнал Байкальского государственного университета 
В настоящее время нарушением при ограничении права на свободу и личную неприкосновенность остается то, что в обоснование необходимости применения ареста кладутся зачастую не конкретные факты, а тяжесть преступления и гипотетическая возможность воспрепятствования расследованию или совершению новых преступлений. Вместе с тем, ограничения прав, применяемые правоохранительными органами, должны быть адекватны и отвечать назначению уголовного судопроизводства, указанному в ст. 6 Уголовно-процессуального кодекса (УПК РФ), и не более того.

Федеральным законом от 29 декабря 2009 г. № 383-Ф3 (далее - Ф3 № 383) «О внесении изменений в часть первую Налогового кодекса Российской Федерации и отдельные законодательные акты Российской Федерации» были внесены поправки в ст. 108 УПК РФ, а именно в нее был добавлен п. 1.1, в котором содержится запрет на применение меры пресечения в виде заключения под стражу в отношении лиц, подозреваемых (обвиняемых) в отдельных преступлениях в сфере экономики. Эти преступления связаны, в основном, с предпринимательской деятельностью.

Как думается, изменения, внесенные ФЗ № 383, ознаменовали новую страницу в истории уголовного судопроизводства. Практика избрания мер уголовно-процессуального принуждения, оставшаяся с советских времен, сохранялась на протяжении длительного времени и, в какой-то части, продолжает действовать. Порочность такой практики, как я полагаю, заключается в том, что с отказом от социалистического пути развития государства и общества и началом капиталистического отдельные нормы уголовно-процессуального законодательства остались прежними. Такие нормы, нуждающиеся в изменении, не вписываются в существующую модель развития государства и, соответственно, его правовых институтов. Так, правовое регулирование права на свободу и личную неприкосновенность долгое время оставалось наследием прошлой социалистической системы развития общества, не подвергаемой модернизации. Относительно мер пресечения это выражалось в том, что в советский период большинство экономических преступлений совершались против социалистической либо государственной собственности. Многие из таких преступлений считались тяжкими либо особо тяжкими. Как следствие, наказания за такие преступления, по меркам сегодняшнего дня, были очень строги. Соответственно, мерой пресечения за такие преступления нередко избиралось заключение под стражу. В настоящее время наказания за преступления против государственной собственности несоизмеримо мягче, к тому же большинство объектов собственности теперь находится «в частных руках» .

В современной системе строительства государства приоритетной объявлена триада «личность - общество - государство», где интересы и права личности должны защищаться в первую очередь, поэтому преступления против личности теперь считаются наиболее опасными. Общественная опасность преступлений в сфере экономики, в свою очередь, объявлена более низкой. До изменений УПК РФ 2009 г. этот факт оставался неучтенным, заключение под стражу применялось в большинстве дел. Такие изменения УПК РФ, как представляется, положили начало модернизации уголовно-процессуального законодательства, приведению его в соответствие с принятой ныне моделью государственного и общественного развития.

Однако еще не все устаревшие элементы законодательства обновлены. К таким элементам относится и терминология провозглашенного в Конституции РФ права каждого на свободу и личную неприкосновенность, употребляемая в российском уголовно-процессуальном законе. Так, нам думается, необходимо изменить название ст. 10 УПК РФ «Неприкосновенность личности».

Необходимость изменений обусловлена следующими причинами:

- несоответствие названия ст. 10 УПК РФ международно-правовым документам и Конституции РФ;

\section{Baikal Research Journal}

электронный научный журнал Байкальского государственного университета 
- несоответствие название ст. 10 УПК РФ общему содержанию уголовно-процессуального законодательства;

- необходимость продолжить обновление и совершенствование законодательства, регулирующего применение мер уголовно-процессуального принуждения.

Несоответствие названия ст. 10 УПК РФ Конституции РФ и международно-правовым актам проявляется в различии формулировок, употребляемых в них. Если ч. 1 ст. 22 Конституции РФ ( ККаждый имеет право на свободу и личную неприкосновенность») коррелирует со ст. 3 Всеобщей декларации прав человека («Каждый человек имеет право на жизнь, на свободу и на личную неприкосновенность» $)^{2}$ и ст. 5 Конвенции о защите прав человека и основных свобод («Каждый имеет право на свободу и личную неприкосновенность») $)^{3}$, то название ст. 10 УПК РФ не соответствует ни одному из этих основополагающих документов. Как видно, формулировка ч. 1 ст. 22 Конституции РФ пришла из международного права, из основных для России международно-правовых актов.

Конституция РФ установила новую систему прав и свобод человека. Произошла смена модели развития государства. Эта система отличается от предыдущей, закрепленной в Конституции СССР 1977 г. ${ }^{4}$ Изменения затронули и естественное право каждого на свободу и личную неприкосновенность. В ст. 54 Конституции СССР 1977 г. содержались гарантии неприкосновенности личности граждан СССР. Этой статье и соответствовала ст. 11 УПК РСФСР 1960 г. ${ }^{5}$ «Неприкосновенность личности». В ныне действующем УПК РФ наименование статьи, гарантирующей анализируемое право, было взято из УПК РСФСР 1960 г. и стало употребляться без оглядки на современную Конституцию РФ. Думается, что терминологию необходимо привести в соответствие с Конституцией РФ. Наименование ст. 10 УПК РФ должно коррелировать с формулировкой ст. 22 последней. Необходимо обновить этот устаревший элемент уголовно-процессуального законодательства.

Несоответствие названия ст. 10 УПК РФ «Неприкосновенность личности» общему содержанию уголовно-процессуального законодательства проявляется в несоответствии объема содержания понятия неприкосновенность личности и в том, что оно не полностью отражает содержание этого права в уголовном судопроизводстве. Термин «личность», как думается, является более широким по содержанию в отличие от термина «лицо» и не может употребляться в уголовно-процессуальном законодательстве в том виде, в каком он употреблен в ст. 10 УПК РФ, по следующим причинам.

В соответствии со словарем С. И. Ожегова, личность - это «человек как носитель каких-н. свойств, лицо» [11, с. 330]. Лицо же определяется как «человек, личность» [Там же, с. 329-330]. Словарь В. И. Даля практически отождествляет слова «лицо» и «личность»: лицо - «особа, человек», личность - «лицо, самостоятельное, отдельное существо» [12, с. 667]. На основании определений толковых словарей можно заключить, что под «личностью» подразумевается человек как носитель каких-либо свойств, позволяющих отличить его от других людей. Думается, что в рамках уголовного судопроизводства такое лицо, человек, как обладатель каких-либо свойств, не представляет особого интереса. Термин «личность» в УПК РФ употребляется, например, при сборе «обстоятельств, характеризующих личность обвиняемого», включаемых в предмет доказывания (подп. 3 п. 1 ст. 73

\footnotetext{
${ }^{2}$ Всеобщая декларация прав человека : принята 10 дек. 1948 г. // Российская газета. 1995. 5 апр.

${ }^{3}$ Конвенция о защите прав человека и основных свобод : принята 4 нояб. 1950 г. // Собрание законодательства Российской Федерации. 2001. № 2. Ст. 163.

${ }^{4}$ Конституция (Основной Закон) Союза Советских Социалистических Республик : принята 7 окт. 1977 г. Верховным Советом СССР // Ведомости Верховного Совета СССР. 1977. № 41. Ст. 617.

5 Уголовно-процессуальный кодекс РСФСР [Электронный ресурс] : закон РСФСР от 27 окт. 1960 г. // СПС «КонсультантПлюс» .
}

\section{Baikal Research Journal}


УПК РФ) либо при установлении личности участника уголовного судопроизводства перед началом следственного действия (ч. 5 ст. 164 УПК РФ) или судебного заседания (ч. 1 ст. 265 УПК РФ). Соответственно, термин «неприкосновенность личности" может включать в себя право на неприкосновенность не только самого человека, но и каких-либо его интересов, что является лишним для целей уголовного судопроизводства.

В этой связи представляется, что термин «личность» необходимо заменить на употребляемый как в Конституции РФ, так и в международно-правовых актах термин «каждый». Такая замена терминов позволит: во-первых, обеспечить соответствие названия ст. 10 УПК РФ как международно-правовым актам и Конституции РФ, так и общему содержанию УПК РФ; во-вторых, исключить употребление в уголовно-процессуальном законодательстве терминов, имеющих более широкое значение, чем необходимо в уголовном судопроизводстве. Так, использование декларативной формулировки «личность», более применимо, например, в конституционном праве, так как это дает возможность обосновывать существование других прав и свобод человека, производных от провозглашенного в ч. 1 ст. 22 Конституции РФ права на свободу и личную неприкосновенность, но в рамках уголовного судопроизводства необходимо руководствоваться более узким содержанием этой статьи.

Вместе с тем, при применении к лицу мер уголовно-процессуального принуждения затрагивается не только право на личную неприкосновенность, но и право на свободу, что, как мне думается, тоже должно быть отражено в названии ст. 10 УПК РФ. Подозреваемый, обвиняемый, подсудимый имеют право на получение той меры свободы, которая возможна в отдельном уголовном судопроизводстве.

В первую очередь в ходе уголовного судопроизводства ограничивается право на личную неприкосновенность (например, при задержании либо личном обыске (ст. 93, 182, 184 УПК РФ)), а только потом и право на свободу (например, при применении и последующем продлении меры пресечения в виде заключения под стражу (ст. 108, 109 УПК РФ)). Соответственно, название ст. 10 УПК РФ должно быть сформулировано таким образом: на первом месте право на личную неприкосновенность, а на втором - право на свободу. Указание же именно на «личную» неприкосновенность позволит отличать ее от других видов неприкосновенности в уголовном судопроизводстве, например, от неприкосновенности жилища.

Полагаем также следующее: в УПК РФ должно быть отражено, что личная неприкосновенность и свобода являются именно правом. Такое добавление подчеркнет, что это право принадлежит каждому человеку и оно должно ограничиваться только в действительно необходимых случаях. Используемое ныне наименование ст. 10 УПК РФ «Неприкосновенность личности», как думается, не отражает предназначения и цели закрепления гарантий этого права в уголовном судопроизводстве. Считаем, что название анализируемой статьи должно указывать на гарантии именно права каждого на личную неприкосновенность и свободу в уголовном судопроизводстве.

На основании изложенных доводов предлагаем изменить название ст. 10 УПК РФ с «Неприкосновенность личности» на «Право каждого на личную неприкосновенность и свободу», поскольку это позволит добиться следующих положительных моментов:

- соответствие международно-правовым документам и Конституции РФ;

- корреляция с общим содержанием уголовно-процессуального законодательства;

- обновление и совершенствование законодательства, регулирующего применение мер уголовно-процессуального принуждения.

\section{Baikal Research Journal}

электронный научный журнал Байкальского государственного университета 


\section{Список использованной литературы}

1. Смолькова И. В. Великие и знаменитые о мерах пресечения / И. В. Смолькова // Сибирские уголовно-процессуальные и криминалистические чтения : сб. науч. тр. / гл. ред. А. А. Протасевич. - Иркутск : Изд-во БГУЭП, 2009. - Вып. 1 (2). - С. 131-144.

2. Теория государства и права / под ред. В. К. Бабаева. - М. : Юрайт, 2014. - 715 с.

3. Нудненко Л. А. Конституционное право России / Л. А. Нудненко. - М. : Юрайт, 2013. $-606 \mathrm{c.}$

4. Комкова Г. Н. Конституционное право Российской Федерации / Г. Н. Комкова, Е. В. Колесников, М. А. Липчанская. - М. : Юрайт, 2013. - 457 с.

5. Теория государства и права / отв. ред. А. В. Малько. - М. : КноРус, 2009. - 400 с.

6. Серекова Е. Ю. Защита права на свободу и личную неприкосновенность человека в решениях Конституционного Суда РФ / Е. Ю. Серекова // Адвокат. — 2010. — № 2. — С. 59-66.

7. Серекова Е. Ю. Конституционно-правовая технология как средство повышения эффективности защиты права на свободу и личную неприкосновенность человека Конституционным Судом РФ / Е. Ю. Серекова // «Черные дыры» в Российском законодательстве. 2010. - № 2. - С. 16-19.

8. Мазюк Р. В. О продолжительности процессуального статуса подозреваемого в случае применения к нему меры пресечения до предъявления обвинения / Р. В. Мазюк // Российский следователь. - 2013. - № 11. - С. 17-20.

9. Парфенова М. В. Конституционное право на свободу и личную неприкосновенность в досудебных стадиях уголовного процесса / М. В. Парфенова // Уголовное право. — 2002. № 4. - С. 58-59.

10. Руднев В. И. О необходимости разработки новых мер пресечения, альтернативных заключению под стражу / В. И. Руднев // Журнал российского права. — 2009. — № 6. C. $60-65$.

11. Ожегов С. И. Толковый словарь русского языка / С. И. Ожегов, Н. Ю. Шведова. 4-е изд. - М. : Азбуковник, 1999. - 940 с.

12. Даль В. И. Толковый словарь живого великорусского языка : в 4 т. / под ред. И. А. Бодуэна де Куртенэ. - М. : ТЕРРА-Кн. клуб, 1998. — Т. 2. - 779 с.

\section{References}

1. Smolkova I. V. The great and the famous about coercion measures. In In Protasevich A. A. (ed.). Sibirskie ugolovno-protsessual'nye i kriminalisticheskie chteniya [Siberian criminal procedure and forensic reading]. Irkutsk, Baikal State University of Economics and Law Publ., 2009, iss. 1 (2), pp. 131-144. (In Russian).

2. Babaev V. K. (ed.). Teoriya gosudarstva i prava [Theory of State and Law]. Moscow, Yurait Publ., 2014. 715 p.

3. Nudnenko L. A. Konstitutsionnoe pravo Rossii [Constitutional Law of Russia]. Moscow, Yurait Publ., 2013. 606 p.

4. Komkova G. N., Kolesnikov E. V., Lipchanskaya M. A. Konstitutsionnoe pravo Rossiiskoi Federatsii [Constitutional law of the Russian Federation]. Moscow, Yurait Publ., 2013. 457 p.

5. Mal'ko A. V. (ed.). Teoriya gosudarstva i prava [Theory of State and Law]. Moscow, KnoRus, Publ., 2009. 400 p.

6. Serekova E. Yu. Defense of rights for liberty and personal inviolability in decisions of the RF Constitutional Court. Advokat = Lawyer, 2010, no. 2, pp. 59-66. (In Russian).

7. Serekova E. Yu. Constitutional and legal technology as a means of increasing efficiency of defending the right for liberty and personal inviolability by the RF Constitutional Court. «Chernye dyry» $v$ Rossiyskom Zakonodatel'stve = «Black Holes» in Russian Legislation, 2010, no. 2, pp. 16-19. (In Russian).

8. Mazyuk R. V. On duration of procedural status of the suspect in case of initiating coercion measures against him before bringing the charge. Rossiiskii sledovatel' = Russian Investigator, 2013, no. 11, pp. 17-20. (In Russian).

9. Parfenova M. V. Constitutional right for freedom and personal inviolability at pre-trial stage of criminal procedure. Ugolovnoe pravo = Criminal Law, 2002, no. 4, pp. 58-59. (In Russian).

10. Rudnev V. I. On necessity of developing new preventive measures alternative to custody. Zhurnal rossiiskogo prava = Journal of Russian Law, 2009, no. 6, pp. 60-65. (In Russian).

\section{Baikal Research Journal}


11. Ozhegov S. I., Shvedova N. Yu. Tolkovyy slovar' russkogo yazyka [Definition Dictionary of the Russian Language]. $4^{\text {th }}$ ed. Moscow, Azbukovnik Publ, 1999. 940 p.

12. Dal' V. I.; Boduen de Kurtene I. A. (ed.). Tolkovyi slovar' zhivogo velikorusskogo yazyka [The Explanatory Dictionary of the Living Great Russian Language]. Moscow, TERRA-Knizhnyi klub Publ., 1998. Vol. 2. 779 p.

\section{Информация об авторе}

Преловский Павел Олегович - аспирант, кафедра уголовного права, криминологии и уголовного процесса, Юридический институт, Байкальский государственный университет, 664003, г. Иркутск, ул. Ленина, 11, e-mail: ppo-ur@mail.ru.

\section{Author}

Pavel O. Prelovsky - PhD Student, Chair of Criminal Law, Criminology and Criminal Procedure, Juridical Institute, Baikal State University, 11 Lenin St., 664003, Irkutsk, Russian Federation; e-mail: ppo-ur@mail.ru.

\section{Библиографическое описание статьи}

Преловский П. О. Право на свободу и личную неприкосновенность в российском уголовном судопроизводстве: терминологические проблемы / П. О. Преловский // Baikal Research Journal. — 2016. — T. 7, № 5. — DOI : 10.17150/2411-6262.2016.7(5).21.

\section{Reference to article}

Prelovsky P. O. Right for liberty and personal inviolability in Russian criminal procedure: terminological problems. Baikal Research Journal, 2016, vol. 7, no. 5. DOI : 10.17150/24116262.2016.7(5).21. (In Russian).

\section{Baikal Research Journal}

